INVESTIGACIÓN

Recibido:17/11/2021 ---- Aceptado:02/12/2021 --- Publicado: 03/01/2022

\title{
EL HÉROE DUAL EN EL CAPITALISMO TARDÍO. NUEVOS LENGUAJES DEL MITO EN $V$ DE VENDETTA y MR ROBOT
}

The dual hero in late capitalism. Myth' new languages in $v$ for vendetta and Mr. Robot

(D) Paula Requeijo Rey. Universidad Complutense de Madrid. España p.requeijo@ucm.es

Eva Aladro Vico. Universidad Complutense de Madrid. España. ealadro@ucm.es

\section{Cómo citar el artículo:}

Requeijo Rey, P., y Aladro Vico, E. (2022). El héroe dual en el capitalismo tardío. Nuevos lenguajes del mito en v de vendetta y Mr. Robot. Vivat Academia. Revista de Comunicación, 155, 219-239. http://doi.org/10.15178/va.2022.155.e1416

Financiación: Esta investigación forma parte del Proyecto Europeo AGLAYA-CM: Estrategias de Innovación en Mitocrítica Cultural. Unión Europea, Fondos Estructurales. Universidad Complutense, Universidad Autónoma de Madrid, Universidad Carlos III, Universidad de Alcalá, Universidad Pontificia de Comillas, Universidad Antonio de Nebrija y Universidad Francisco de Vitoria con una financiación de 208.380 euros. Cursos 2019-2020 y 2020-2021. Dirigido por el Catedrático del Departamento de Filología Francesa de la Universidad Complutense José Manuel Losada Goya. Project number: H2019/HUM-5714.

\section{RESUMEN}

Esta investigación analiza la presencia y características del denominado héroe dúplice o ambivalente en dos distopías críticas que abren y cierran el capitalismo tardío: el cómic $V$ de Vendetta (1982-1988) y la serie Mr Robot (2015-2019). El héroe dúplice ya está presente en los mitos arcaicos. Sin embargo, se desdibujó para dar paso a arquetipos más delimitados. Las narraciones del capitalismo tardío, en el que han proliferado la distopía crítica y la ciencia ficción, recuperan a este héroe dúplice. Sirviéndonos de una profunda revisión bibliográfica que nos permite conectar las teorías de distintos estudiosos del mito y del análisis detallado de estas dos distopías críticas influidas por la ciencia ficción, comprobamos cómo los mitos se adaptan a las disfunciones y complicaciones de la vida actual. Mediante una crítica a las incongruencias sociales y económicas del neoliberalismo y la sociedad digital los héroes dúplices de $V$ de Vendetta (1982-1988) y la serie Mr Robot (2015-2019) apuntan un sentido liberador en relación con el contexto actual. Ambos textos ofrecen una 
especie de venganza o compensación además de reflejar la confusión en los valores en el capitalismo tardío.

PALABRAS ClAVE: Ciencia ficción - Distopía crítica - Capitalismo tardío Neoliberalismo - Sociedad digital - Mito - Héroe dúplice.

\section{ABSTRACT}

This research analyzes the presence and characteristics of the so-called dual or ambivalent hero in two critical dystopias that open and close late capitalism: the comic V for Vendetta (1982-1990) and the Mr. Robot series (2015-2019). The dual hero is already present in archaic myths. However, it was blurred to give way to more defined archetypes. The narratives of late capitalism, in which critical dystopia and science fiction have proliferated, recover this duplicitous hero. Using a complete bibliographic review that allows us to connect the theories of different scholars specialized in myth study and through the detailed analysis of these two critical dystopias influenced by science fiction, we verify how myths adapt to the dysfunctions and complications of current life. Through a critique of the social and economic incongruities of neoliberalism and the digital society, the duplicitous heroes of $V$ for Vendetta and Mr Robot point to a liberating sense in relation to current context. Both texts offer a kind of revenge or compensation and reflect the confusion in values in late capitalism.

KEY WORDS: Science fiction - Critical dystopia - Late capitalism - Neoliberalism Digital society - Myth - Dual hero.

\section{O DUPLO HERÓI NO CAPITALISMO TARDIO. NOVAS LÍNGUAS DO V- MITO DE VENDETTA e MR ROBOT}

\section{RESUMO}

Esta pesquisa analisa a presença e as características do chamado herói dúbio ou ambivalente em duas distopias críticas que abrem e fecham o capitalismo tardio: a história em quadrinhos V de Vingança (1982-1988) e a série Mr Robot (2015-2019). O duplo herói já está presente nos mitos arcaicos. No entanto, foi desfocado para dar lugar a arquétipos mais delimitados. As narrativas do capitalismo tardio, em que proliferaram a distopia crítica e a ficção científica, recuperam esse duplo herói. Por meio de uma profunda revisão bibliográfica que nos permite conectar as teorias de diferentes estudiosos do mito e uma análise detalhada dessas duas distopias críticas influenciadas pela ficção científica, verificamos como os mitos se adaptam às disfunções e complicações da vida atual. Por meio de uma crítica às incongruências sociais e econômicas do neoliberalismo e da sociedade digital, os heróis dúbios de $\mathrm{V}$ for Vendetta (1982-1988) e da série Mr Robot (2015-2019) apontam para um sentido libertador em relação ao contexto atual. Ambos os textos oferecem uma espécie de vingança ou compensação, além de refletir a confusão de valores no capitalismo tardio. 
PALAVRAS-CHAVE: Ficção científica - Distopia crítica - Capitalismo tardio Neoliberalismo - Sociedade digital - Mito - Duplo herói.

\section{INTRODUCCIÓN}

La ciencia ficción y la utopía en sus diversas formas son géneros diferentes pero tienen una serie de características comunes. Una de las más destacadas es que actúan como un espejo de "nuestras esperanzas y miedos sobre el futuro" en relación con "la ciencia y la tecnología" (Fitting, 2010, p. 3) buscando que el público se cuestione determinados aspectos de la realidad actual o próxima. Nos presentan espacios y tiempos que parecen no corresponderse con los nuestros pero que nos remiten a ellos para plantearnos qué podría ocurrir si evolucionáramos en un determinado sentido o cómo impactaría socialmente el uso que le damos a la tecnología. Este aspecto es tan importante en ambos géneros que hay autores que consideran que es imposible estudiar las utopías y distopías del último medio siglo sin atender a la ciencia ficción (Fitting, 2010).

Otro de los puntos comunes entre ciencia ficción y distopía es la influencia que los acontecimientos sociohistóricos ejercen sobre ambas. De hecho, la distopía tiene en el siglo XX su momento de máxima producción debido a los acontecimientos que lo definieron: guerras mundiales, genocidios, ecocidios, crisis económicas y la mercantilización de todas las dimensiones del individuo (Moylan, 2018). Como consecuencia el ciudadano medio y numerosos intelectuales perdieron la confianza en el progreso (López Keller, 1991).

La utopía resurgió en la década de los 70 con la segunda ola del feminismo y la contracultura pero, desde los años 80 hasta ahora, estamos en un período de claro triunfo de la distopía (Moylan, 2018). La razón está en la implantación a escala global del modelo económico neoliberal que ha supuesto el desmantelamiento del Estado del Bienestar y la bajada del salario de los trabajadores (Hermida, 2000). La profunda crisis económica, política, institucional y de valores en la que estamos sumidos desde 2008 demuestra que ese Estado del Bienestar es una entelequia o bello sueño.

El capitalismo tardío, caracterizado por este neoliberalismo global y por la sociedad de masas e hiperconsumo, está representado por un género: la distopía crítica (Moylan, 2018). Una distopía crítica que pone el acento en los fallos y problemas del presente, preocupada por sus repercusiones en el futuro cercano y que demanda una estructura que nos sirva mejor como especie. Esto lo recogen también las obras de ciencia ficción que cuestionan el uso de la ciencia y la tecnología dentro del sistema.

En este contexto, ¿qué ocurre con los protagonistas de las distopías críticas y de los relatos de ciencia ficción contemporáneos? La hipótesis de partida de esta investigación, que analiza dos estudios de caso, la novela gráfica de ciencia ficción y distopía crítica $V$ de Vendetta y la distopía crítica Mr. Robot, es que presentan héroes con una identidad dual, ambigua, que supone la unión de contrarios. 
Estas figuras dúplices ya están presentes en formas mitológicas arcaicas y antiguas. Responden a lo que Jung (1951) denominó "la sombra" y tienen relación con nuestra propia naturaleza. Sin embargo, la crisis permanente que caracteriza el capitalismo tardío ha hecho proliferar este tipo de figuras junto a la del villano. Forman parte de "un modelo perverso de recepción" en el que el público se proyecta e identifica con protagonistas que se oponen a los valores tradicionales del héroe o bien encarnan modelos de explícita maldad (Fernández Pichel, 2013, p. 105). Como veremos en los próximos apartados, nuestros dos casos de estudio se corresponden con el primer tipo de personaje.

Podríamos pensar que los mitos presentes en estas distopías críticas y relatos de ciencia ficción protagonizados por héroes "sombra" o villanos son oscurantistas, confusionarios. Sin embargo, los dos casos de estudio analizados, responden a mitos iluminadores que clarifican la complejidad social actual. Plantean una lectura crítica y apuntan un sentido liberador en relación con una estructura social global, interconectada y profundamente desigual.

\section{MARCO TEÓRICO}

\subsection{Posmodernismo y capitalismo tardío}

Entendemos por posmodernismo, siguiendo a Lyotard, un "estado de pensamiento" caracterizado por la falta de confianza en los "grandes relatos": "ya no son creíbles ni bastan para asegurar como pretendían un compromiso político, social y cultural" (1992, p. 2). Entonces, ¿en qué cree y con qué está comprometido el individuo posmoderno? Con el consumo. No se trata sólo de productos y servicios. Los conceptos de mercancía, productividad y eficacia se aplican al mismo ser humano y a sus relaciones que se convierten en objetos ${ }^{1}$.

Esto ocurre en virtud de un proceso de "adiestramiento mental" con el objetivo de ejercer un control ya que "el consumo desarma la virulencia social" (Baudrillard, 2007, p. 85). Las democracias posteriores a la Segunda Guerra Mundial se fundaron y legitimaron en la igualdad de derechos y deberes de los ciudadanos. Sin embargo, la experiencia del individuo le demuestra a diario que se trata de una quimera:

El sistema se apoya mucho más eficazmente en un dispositivo inconsciente de integración y de regulación. Y éste consiste, a diferencia de la igualdad, en implicar a los individuos en un sistema de diferencias, en un código de signos.

\footnotetext{
${ }^{1}$ El concepto de mercancía y su lógica se aplican, incluso, a las relaciones de amistad. En este sentido, a las autoras les llama especialmente la atención que hayan surgido empresas para "alquilar amigos" como AlquiFriend https://www.alquifriend.com/ o Alquila un amigo https://www.alquilaunamigo.one/. En la primera página web se puede ver la fotografía junto a una breve descripción de la persona que se "alquila como amigo". Por 20 euros la hora, aproximadamente, acompañan a quien pague por sus servicios al cine, a una fiesta o a comer.
} 
Eso es la cultura, eso es el lenguaje y eso es el consumo en el sentido más profundo del término (Baudrillard, 2007, p. 103).

De ahí que Jameson bautizara al posmodernismo como la lógica cultural del capitalismo tardío: "la nueva formación social ya no obedece las leyes del capitalismo clásico, o sea, la primacía de la producción industrial y la omnipresencia de la lucha de clases" (1991, p. 17). El ciudadano es aquí un mero consumidor que está permanentemente deseando desear. Busca el placer inmediato, la satisfacción instantánea obteniendo, en cambio, una insatisfacción permanente de sus necesidades.

En los últimos doce años la crisis, corazón del posmodernismo, se ha materializado en una acción: la del desplome. Se han desplomado la economía, la política y las instituciones. Se ha desplomado el ya poco extendido Estado del Bienestar y, con él, el ascensor social y los valores y aspiraciones de varias generaciones. La identidad que corresponde al individuo en esta estructura socioeconómica es la que Bauman (2001) metaforizó como líquida por su permanente inestabilidad y precariedad. El núcleo de la misma son lógicamente la ansiedad, la angustia y el miedo.

\subsection{El héroe dual o ambivalente: del pasado al presente \\ 2.2.1. Antecedentes de mitología arcaica}

La ambivalencia del héroe en forma mítica es un rasgo de arcaísmo y de profundidad psicológica a la vez. Campbell y Jung estudiaron arquetipos y mitos en los que la "sombra" y lo dual estaban muy presentes. Los dos autores mostraron cómo en las formas arcáicas del héroe, este aspecto dual, distópico/utópico, era central. En la raíz de los mitos que conforman los monomitos del Héroe (Campbell, 1959), aparece una idea de identidad que en muchos casos no es autoafirmativa, sino trágica, dual, ambigua u oximorónica (de contrarios unidos).

Podemos rastrear este rasgo dúplice y ambivalente, contradictorio y supramoral, de las formas identitarias del mito hasta muy antiguas manifestaciones, como las de los héroes de naturaleza dual animal/humano y los héroes enantiodrómicos (buenos y malos a la vez, vivos y muertos a la vez). Algunos ejemplos los encontramos en las formas de andróginos en el Neolítico, antropozoos y mitos duales mortíferos/creadores (Deméter, Dionisos).

Mucho más antigua es la representación identitaria dúplice o doble en las formas de las diosas y dioses que estudió Marija Gimbitas en su arqueomitología de las representaciones simbólicas humanas (Gimbutas 2014; 2019). Coincidiendo con los arquetipos junguianos que expresan misterios de conjunción y unión de contrarios, los dioses y formas mitológicas más arcaicas del mundo nos presentan síntesis en las que los aspectos humano/no humano, vivo/no vivo, trascienden la representación del ser vivo, y del dios o héroe, como la muy arcaica diosa-pájaro o las formas de divinidad dual como la diosa azteca Coatlicue. 
Podemos también rastrear en las manifestaciones míticas la expresión de la sombra identitaria, en su doble aspecto, de canalización de las formas rechazadas y oscuras del yo, pero también, en su aspecto de impulsos idealistas, creadores, forjadores de mundo. La fuerza de los mitos proviene seguramente de su conexión con la "sombra" de nuestra propia conciencia (Jung, 2002, p. 112). Como totalidad, el ser de cada individuo es una complejidad inconciliable, una "coincidentia opositorum". Los mitos expresan la identidad psíquica humana, ya estén canalizados en la alquimia, en las religiones, en las obras creativas del arte, o en los movimientos sociales, poniéndonos en conexión con el yo profundo (Jung, 2002, p. 445). La sombra de la personalidad individual es la conformación de todos aquellos aspectos del sí mismo profundo que la persona no reconoce como propios.

En Aión (2011) Jung plantea cómo, con el avance del tiempo, las formas antagonistas de la sombra individual fueron escindiéndose, pasando a estar personificadas en imágenes y seres del mal mucho más delimitados, tal y como ocurre en la simbología cristiana. La contraposición de lo luminoso y bueno, por un lado, y de lo oscuro y malo, por otro, que a menudo en la visión mítica del dios o del héroe estaban unidas indisolublemente, quedó abandonada abiertamente y dejado de lado su carácter complejo. Por ejemplo: Cristo representa al bien sin más, y el opositor de Cristo, el Diablo, representa el mal.

El concepto de sombra en Jung es importante por su complementariedad con las formas afirmativas del yo. Todos tenemos un aspecto dual del yo, que se manifiesta en arquetipos duales -héroes/antihéroes, dioses/demonios-. El psicólogo suizo relaciona esto con la naturaleza de nuestra consciencia bicameral, además de con el reconocimiento del aspecto incógnito y misterioso del Yo. Para Campbell, el héroe también representa aspectos contradictorios, e incluso con ellos se expresa mejor el carácter doble, material/inmaterial, del ser humano, y su relación con la vida y la muerte.

\subsubsection{Mitos y medios de masas}

En la modernidad, la proyección del héroe no solo no pierde este carácter dual, sino que se acentúa. Hacemos una canalización de baja energía (Jung, 2008; Aladro, 2013) cuando figuramos en los héroes de nuestra creación y ficción creativa las antiguas formas complejas y misteriosas del héroe dual. Los héroes modernos son héroes dúplices, trágicos, héroes a su pesar, héroes de aspectos sombríos o con una naturaleza equívoca. También la dualidad se manifiesta en una doble naturaleza: héroes inhumanos/humanos, héroes vivos/muertos, o héroes con nombre/anónimos. Y una de las formas más persistentes en las creaciones más modernas son los héroes de doblez moral, o con una doble moral, o doble rostro moral. Estas formas pueden interpretarse también como arquetipos del alma o la psique -que también es algo dúplice- $\mathrm{y}$, por supuesto, como arquetipos de la existencia actual, marcada por las contradicciones y las polaridades indestructibles naturaleza y tecnología, amor y egoísmo, razón y sentimiento, etc-. 
Lo que el mito intenta en toda época, con más o menos energía de raíz, es poner en comunicación nuestra existencia con nuestro más profundo espíritu (Campbell, 2016) para poder integrar en él lo que difícilmente puede conciliarse. Este proceso, psicológicamente, es la unión de contrarios que tanto interesó a Mircea Eliade en sus estudios sobre el simbolismo (Eliade, 1999; 2005). La unión en un eje humano, en un héroe, de aspectos contrarios, es una fuente de expresividad en todas las culturas.

La comunicación de masas y sus sistemas proyectivos introducen un factor importante de revitalización de los aspectos bipolares de los héroes en sus relatos de ficción y en sus mitos. Ello es así porque esta cultura permite materializar y reproyectar contenidos profundos de la psique humana mediante sus industrias culturales: el cine, el cómic, la radio, la televisión, etc... Como analiza Morin, el mundo de la proyección imaginaria que la tecnología de los medios de masas genera en el siglo XX supone una importante extensión de las formas de los héroes y los mitos (Morin, 2001).

Este autor francés estudia al "doble" en el hombre imaginario de la comunicación creativa de los medios. Este "doble" cumple funciones de identificación. En el "siglo del Yo", como ha sido bautizado el siglo XX, las formas de héroe del cine, la novela o los cómics, presentan la dualidad como un factor clave de su origen, su desarrollo y su capacidad identificativa. La representación del alma moderna toma así la forma de duplicidad que encaja con la doble naturaleza, material e imaginaria, de la cultura de masas.

Hay un caso paradigmático a la hora de representar las funciones de las simbologías del mito en la cultura de masas que responde al arquetipo del misterio de conjunción o "enantiodromos": el "cinemito" de Frankenstein (Picart, 2003). Se trata de un ser híbrido, dual, humano-inhumano, que expresa la realidad de lo imposible o inconciliable en la tecnología y la ciencia (Jung, 2002). Materializa, identifica y naturaliza el temor humano a una creación científica o tecnológica que puede controlar y suplantar a la persona. La expresión de los miedos, pero también la expresión de las discontinuidades entre la tecnología y nuestros cuerpos, están llamando al mito del Frankenstein.

De ahí que, la forma tecnológica última de Frankenstein, el cíborg protagonice numerosos textos (películas, series, novelas, etc...) actuales que funcionan como sombras distópicas (Picart, 2003). Está presente también en la inteligencia artificial, los drones vigilantes o los bots.

Este mito ha ramificado además en fisionomías sociopolíticas. Pensemos en movimientos donde la representación de la identidad de grupo aparece como un ser híbrido, una máscara o una "sombra": del grupo Anonymous al artista Banksy, del movimiento Cyborg a los rebeldes sin líder de los paraguas amarillos en Hong Kong. Estas iniciativas de cambio social, usando el lenguaje de la creación, dan fuerza a su acción colectiva (Aladro, Jivkova y Bailey, 2018). 
Por tanto, Frankenstein, el gólem, el cíborg o el hombre artificial en sus formas digitales integran una cadena simbólica con reincidencia de una mitología con una larga historia cultural, que regresa ante la conformación del mundo tecnológico actual. Mediante esta conexión, los mitos pueden ejercer la función de incitar a la acción evolutiva. Pueden "encapsular" (Miller y McHoul, 1998) contenidos vitales de la existencia humana, articulando dimensiones inconciliables en un lenguaje nuevo y, así, hacer presentes, fácticos y centrales, las innovaciones y avances sociales.

\subsubsection{La ciencia ficción en la era digital}

Los héroes y villanos de la ciencia ficción, género contemporáneo como pocos, están muy marcados por estos rasgos de complementariedad con la sombra y de ambigüedad moral o natural. Es en el mundo moderno, tanto en la cultura de masas como en la alta cultura literaria, donde encontramos héroes como Frankenstein, Nosferatu, el mago Tiresias o Terminator.

La doble naturaleza material, pero sobre todo, la doble naturaleza moral, es un rasgo cada vez más frecuente. La producción audiovisual de los últimos tiempos ha generado narraciones para los villanos de las series o películas (jokers, zombis o asesinos en serie) y muchos de los héroes digitales tienen una cara sombría (Anonymous) o desconocida (Banksy). Los precedentes son muy aislados y es ahora cuando se produce una frecuencia mayor de este tipo de creaciones.

¿Cómo podemos interpretar esta tendencia? Consideramos que, además de conectar con las disociaciones y disyuntivas del mundo contemporáneo o con el desarrollo imaginario de la cultura de masas, estos héroes ambivalentes, de doble naturaleza, están reconectando con los modos profundos de representación simbólica del yo que encontramos en los mitos antiguos.

No es una casualidad que en los modos heróicos de la cultura contemporánea, sean ficcionales o reales, las identidades distópicas se abran paso, con su plena complejidad híbrida. Así, por ejemplo, como caso de hibridación cultural/social marcada por rasgos de los héroes modernos, tenemos la figura de Anonymous, la identidad transgresora que encabeza un movimiento juvenil de gran extensión.

La imagen de Anonymous es una simbolización interesante de la identidad contemporánea, asociada a una cadena arquetípica de gran antigüedad, que ya hemos citado. El héroe anónimo es un arquetipo importante de la personalidad, contradictorio (enantiodromos)-une en su idea la identificación y el anonimato- y responde a una larga cadena de representaciones del héroe -recordábamos el monomito de Campbell-. Pero Anonymous se ancla en la cultura de masas del siglo $\mathrm{XX}$ con la imagen de $V$, protagonista del cómic de ciencia ficción $V$ de Vendetta que, a su vez, nos remite mucho más atrás: a la máscara del conspirador inglés Guy Fawkes que intentó volar el Parlamento británico en la denominada "conspiración de la pólvora" (1605). A su vez, la serie Mr Robot se inspira directamente en las acciones que Anonymous ha desarrollado. 
Anonymous enlaza también con canalizaciones de una figura que nos recuerda a la Parca, al fantasma o a la misma simbolización del rebelde mosquetero, junto al héroe británico del siglo XVII ya mencionado. V, dotado incluso de un símbolo sígnico como es esta letra, traduce en la actualidad una figura indefinida, y cuya valoración no podemos asociar con claridad a un héroe ni a un villano. Es el lector del cómic, o quien visiona la película posterior de 2005, quien decide si sus acciones son salvadoras o vengativas, como los propios miembros de esta comunidad indican. La ambigüedad identitaria y moral es un profundo rasgo mítico.

En los desarrollos culturales actuales, los héroes distópicos proliferan en la ciencia ficción, con aspectos que son clave en la cultura digital actual. Como hemos visto, existe efectivamente una conexión entre sociedad y formalizaciones heróicas, y en la ciencia ficción es posible representar con mayor claridad la conexión, a menudo contradictoria, compleja y misteriosa, entre sociedad e imaginación humana, por un lado, y sociedad e individuo, por otra. En la raíz de esas interacciones es donde reside la riqueza de los desarrollos de héroes modernos que estamos describiendo.

\section{METODOLOGÍA}

Esta investigación cualitativa comprende una serie de pasos metodológicos correlativos. El primero de ellos ha consistido en una revisión bibliográfica profunda de autores relevantes en relación con las categorías de ciencia ficción, distopía, capitalismo tardío, mitos y héroe dual. El segundo paso se centró en la lectura de la novela gráfica $V$ de Vendetta (1982-1990) y en el visionado de las cuatro temporadas de la serie Mr. Robot (2015-2019). El tercer paso se corresponde con el análisis de esos dos textos a partir de las categorías definidas en el primer paso para determinar el peso de las mismas, especialmente la del héroe dual, en las narraciones.

Hemos seleccionado $V$ de Vendetta y Mr. Robot porque consideramos que resumen la respuesta de la ciencia ficción y la distopía crítica a los últimos 40 años de la posmodernidad dominada por el neoliberalismo. $V$ de Vendetta abarca la década que refuerza las bases del neoliberalismo: empieza a publicarse en 1982 y termina en 1990. Se inspira directamente en las acciones del Gobierno de Margaret Thatcher. Como sabemos, tanto su visión político-económica-social como la de Reagan refuerzan este sistema-ideología que utilizó el Chile de Pinochet (1974-1981) y la Argentina de Videla (1976-1981) como laboratorios. Mr. Robot empieza a emitirse en 2015 y termina en 2019. Se inspira directamente en la crisis de 2008 y sus posteriores consecuencias, hasta el punto de incluir imágenes de telediarios y líderes de la vida real.

Creemos que esta amplitud temporal es necesaria ya que nuestro objeto de estudio es el héroe dúplice en dos distopías críticas enmarcadas en la ciencia ficción que tratan de dar respuesta a las contradicciones de la sociedad global, interconectada y profundamente desigual.

\section{DISCUSIÓN}

4.1. Ciencia ficción y distopía crítica en el capitalismo tardío en $V$ de Vendetta 
Novell plantea una clasificación que determina hasta qué grado la ciencia ficción domina una narración a través de tres conceptos: género, modo y fórmula. En este sentido, podemos decir que en $V$ de Vendetta la ciencia ficción es un género porque "sin el contenido cienciaficcional la historia decae y es, de hecho, imposible" (2008, p. 267).

El cronotopo de $V$ de Vendetta, escrita en la década de los 80, es la Inglaterra de 1997 en la que domina un totalitarismo tras la destrucción y el caos de una Guerra Mundial nuclear que ha hecho desaparecer África y Europa. El héroe, V, estuvo internado en el campo de concentración de Larkhill donde la doctora Delia Surridge dirigió un experimento biológico. $\mathrm{V}$ fue el único que sobrevivió y sus capacidades se dispararon. Hizo explotar el campo y planeó una venganza en solitario para la que estas capacidades disparadas son fundamentales.

El objetivo de esta venganza, por encima de su propia satisfacción, es acabar con un sistema injusto cimentado en el miedo, la violencia y el control. Este último se logra, fundamentalmente, a través de una serie de departamentos controlados por el líder del partido fascista que está en el Gobierno, Fuego Nórdico. Estos departamentos se corresponden con partes del cuerpo y con los sentidos: la cabeza, el dedo (antivicio), el ojo (videovigilancia), la oreja (vigilancia telefónica), la nariz y la boca (medios de comunicación).

$V$ de Vendetta se enmarca dentro de la denominada ciencia ficción social ya que se centra "en el futuro de la humanidad a partir de unas determinadas premisas, como puedan ser una catástrofe natural o provocada por el hombre" (López Keller, 1991, p. 21). El hombre ha provocado una guerra nuclear mundial que ha hecho que Fuego Nórdico implante un sistema dictatorial para cuyo funcionamiento es imprescindible la última tecnología.

La inspiración real de esta distopía, según reconoce su guionista, Alan Moore, es la Inglaterra thatcherista caracterizada por impulsar el libre mercado y las privatizaciones (incluida la de la educación), reducir impuestos y debilitar a los sindicatos. Desde el punto de vista social, Thatcher apoyó a la llamada "familia nuclear" o "familia natural" frente a otros tipos (Thomas, 1993) y se opuso a las campañas de sensibilización del VIH, a las que consideraba "de mal gusto" y que "podían dañar a los adolescentes" (Bowcott, 2015).

\section{2. $\quad \mathrm{V}$ como héroe dúplice}

La experiencia de $\mathrm{V}$ en Larkhill le provocó un terrible sufrimiento, pero también le hizo reflexionar sobre la importancia de ser fiel a uno mismo así como de luchar por derrocar el sistema que lo oprimió, vejó, torturó y llegó, incluso, a experimentar con él. La élite que concentra el poder abusa del mismo al humillar, violar y matar a los individuos que carecen de cualquier tipo de autonomía y viven anestesiados y controlados por los medios de comunicación y las tecnologías. 
En el cómic observamos cómo $\mathrm{V}$, que creía en la democracia, queda profundamente decepcionado con ella cuando da paso a un totalitarismo. Simbólicamente, se representa en la subjeción que desarrolla con la estatua de la justicia en el capítulo 5 del libro 1:

V: Te llevo admirando mucho tiempo... aunque sólo a distancia. Solía mirarte desde abajo en la calle cuando era niño. Le decía a mi padre: ¿quién es esa señora? Y él me decía: es la señora justicia. Y yo decía, ¿a qué es preciosa? Por favor, no creas que sólo era algo físico. Sé que no eres esa clase de chica. No. Te amaba como persona, como ideal. Eso fue hace mucho tiempo. Me temo que ahora hay otra (...) Sinceramente, no me sorprendió cuando lo descubrí. Siempre tuviste debilidad por los hombres de uniforme (...) Se llama anarquía y me ha enseñado más como amante que tú en toda tu vida. Me ha enseñado que la justicia carece de sentido sin libertad. Es honesta. No hace promesas. Y no las rompe. No como tú, Jezabel (Moore y Lloyd, 2015, 40-41).

El viaje interior de V como héroe supone un tránsito de la democracia a la anarquía. En una entrevista el propio Moore explicaba que:

Anarquía significa que no haya líderes, y eso parece implicar que si no vas a seguir a un líder, entonces eso requeriría que llegaras a ser tu propio líder, lo que para mí parece implicar tomar responsabilidad sobre ti mismo, tus pensamientos y tus acciones. Lo que pienso es el primer paso para llegar seriamente a algo. El fascismo, en el otro extremo, es una abdicación completa de responsabilidad. Es colocar toda la responsabilidad en el Estado, para que en los juicios por crímenes de guerra puedas decir: simplemente obedecía órdenes. Estos, para mí, parecen ser los dos polos de la política, el fascismo y la anarquía. Todo lo demás casi parece una escala entre ellos (Richards, 2011).

El objetivo de $\mathrm{V}$, por tanto, es derrocar el totalitarismo para lograr que la gente sea libre $\mathrm{y}$, desde esta libertad y con responsabilidad, decida qué sistema quiere construir.

La anarquía tiene dos caras, la creadora y la destructora: los destructores derrocan imperios; crean un lienzo de escombros donde los creadores pueden construir un mundo mejor. Los escombros, una vez conseguidos, convierten en irrelevantes los medios para obtenerlos. ¡Así que fuera con los explosivos! (Moore y Lloyd, 2015, p. 222).

En aras de este objetivo sacrificará su propia vida porque como él mismo dice: "No queda carne ni sangre que matar bajo esta capa. Sólo hay una idea. Las ideas son a prueba de balas" (Moore y Lloyd, 2015, p. 236).

Hasta aquí vemos la parte de $\mathrm{V}$ que se corresponde con los valores del héroe clásico. Ayudará a la joven que va a ser violada por el Obispo Lilliman, un pedófilo, y a Evey Hammond, una chica huérfana de 16 años, cuando está a punto de correr la misma suerte a manos de los agentes de antivicio (dedos). Se deshace del líder del partido, 
de los miembros de sus principales organizaciones y de todos los que asesinaron, torturaron y experimentaron con presos en Larkhill. Emplea la violencia contra un régimen violento y sus criminales.

Sin embargo, la dualidad de este héroe se aprecia claramente en el trato que le dispensa a Evey. La lleva al lugar en el que vive y le enseña distintas cosas. Hasta que un día, sin avisarla, la echa. Evey logra salir adelante gracias a un miembro del partido que la acoge en su casa. Unos meses después, inicia una relación sentimental con él pero es asesinado.

V vuelva a por ella pero, esta vez, la encarcela haciéndole creer que los responsables son los agentes de antivicio. La golpea, la amenaza y la tortura tratando de que confiese que es cómplice de $\mathrm{V}$ y firme una declaración por escrito. Finalmente, cuando Evey muestra que no la firmará y que no le importa que la maten, $\mathrm{V}$ la libera. Lo hace porque cree que ha llegado a entender la esencia de la existencia humana: el ser fiel a uno mismo, a las propias convicciones, está por delante de cualquier cosa.

Porque te quiero. Porque quiero que seas libre (...) Ya estabas en la cárcel. Has estado en la cárcel toda tu vida (...) Yo no te he encarcelado, Evey. Sólo te he mostrado los barrotes (...) Estabas en una celda, Evey. Te ofrecieron escoger entre la muerte de tus principios y la muerte de tu cuerpo. Dijiste que preferías morir (Moore y Lloyd, 2015, p. 167-171).

Evey pasa de ser discípula a maestra: tras su transformación se convierte en la sustituta de $\mathrm{V}$ y, al igual que él, al final del cómic entendemos que formará a otra persona para que a su vez la sustituya.

La sombra de $\mathrm{V}$, por tanto, está en creer que para que alguien se desembarace de todo el adiestramiento al que el régimen lo ha sometido, es necesario que sufra en extremo, que pase por una experiencia traumática como el encierro, los golpes y la tortura. Es cruel y extremadamente violento con una persona inocente, víctima del mismo totalitarismo que él porque considera que si no pasa por su misma experiencia, nunca se transformará.

\subsection{Distopía crítica en el capitalismo tardío en Mr. Robot}

A nivel de género Mr. Robot se ajusta al thriller psicológico y al tecnothriller. Creemos que no se enmarca dentro de la ciencia ficción ni como género ni como modo pese a que reflexiona sobre el uso que le damos a la tecnología y la sociedad injusta, falsa y carente de intimidad a la que ha dado lugar. Sin embargo, sí hay dos aspectos en la serie que se pueden vincular con la ciencia ficción como fórmula. Al hablar de fórmula, siguiendo de nuevo a Novell, nos referimos a "los elementos más icónicos o representativos" del macrogénero sin "su significación de idea cienciaficcional innovadora y se tornan, entonces, en artilugios, ambientes o personajes (...) No es estructural ni de contenido, y se revela más bien como un agregado sin el cual el texto puede funcionar a la perfección" (Novell, 2008, p. 272 y 273). Estos dos aspectos son el proyecto de la líder del Ejército Oscuro, White Rose, de construir una máquina 
que permita revivir a las personas y el hecho de que Tyrell Wellick, con apoyo del Ejército Oscuro, logre jaquear las redes de E Corp y hacer estallar 71 de sus edificios al mismo tiempo.

La distopía que describe Mr. Robot es similar a la realidad de la sociedad actual. La sociedad global del año 2015 que la serie representa sinecdóquicamente a través de la ciudad de Nueva York se sustenta en un capitalismo salvaje y deshumanizado que ha generado profundas diferencias entre las clases. Es también una sociedad digital en la que el día a día de los individuos y sus acciones se rigen por el uso de las nuevas tecnologías y aplicaciones: móviles, ordenadores, redes sociales, etc... Internet y sus derivados, tecnologías configuradas para dejar rastro de la más mínima búsqueda o movimiento, son la base del control social. De hecho, la serie entiende Internet como una herramienta específicamente diseñada para "controlar a los ciudadanos" (4x02) que están continuamente ofreciendo información al sistema.

Es, además, una sociedad falsa en el sentido de fingida o simulada. La mayoría de las personas a las que Elliot jaquea simulan una vida en las RRSS que no se corresponde con la realidad. En algunos casos, además, desarrollan actividades ilegales.

Por último, es una sociedad alienada, donde los individuos se dejan distraer y engañar por diferentes productos culturales que les impiden reflexionar sobre el sistema en el que viven.

Elliot: ¡Sociedad de mierda (...)!

Krista: ¿Qué es lo que tanto te decepciona de la sociedad?

Elliot: No lo sé. ¿Puede ser que todos pensemos que Steve Jobs fue un gran hombre incluso cuando supimos que ganó millones a costa de niños? ¿O quizás porque todos nuestros héroes son un fraude? El mundo en sí es un gran engaño. Nos boicoteamos unos a otros con comentarios de mierda disfrazándonos para ello. Nuestra red social finge ser intimidad. ¿O es que votamos por eso? No en elecciones fraudulentas si no con cosas y pertenencias. Con nuestro dinero. No digo nada nuevo. Todos sabemos por qué Los juegos del hambre nos hace felices. Porque queremos estar sedados. Porque es doloroso no fingir. Porque somos cobardes. ¡Sociedad de mierda! (1x 01).

En ella hay una élite que concentra todos los recursos materiales y financieros.

Elliot: Lo que voy a contaros es alto secreto. Una conspiración más grande que todos nosotros. Un poderoso grupo de personas dirigen el mundo secretamente. Estoy hablando de los tíos que nadie conoce y son invisibles. El $1 \%$ del $1 \%$. Los tíos que juegan a ser Dios sin permiso. Y ahora creo que me están siguiendo $(1 \times 01)$. 
La súper corporación E Corp (Evil Corp), inspirada en Enron (Hernández Santaolalla y Hermida, 2016), detrás de la que está el grupo Deus, similar al Club Bildelberg, representa de forma sinecdóquica a ese 1\%, la élite político-empresarial que viste trajes de chaqueta negros y tiene influencia directa sobre los acontecimientos mundiales: desde guerras hasta crisis económicas. Esta élite controla el destino de la sociedad a través del dinero y las tecnologías.

Los dos casos que funcionan como paradigma de las víctimas del sistema son el mendigo que deja que Tyrell Wellyck le pegue palizas a cambio de 300 dólares y la novia de Elliot en la primera temporada, Shayla, que no quiere denunciar a Fernando Vera, el hombre que la violó, porque es el que le proporciona las drogas que después ella vende para sobrevivir. Elliott Alderson quiere transformar esta distopía en una utopía a través de sus conocimientos informáticos.

Elliot: A veces sueño con salvar el mundo. Salvar a todos de la mano invisible. Esa que nos cuelga la tarjeta de empleado. Esa que nos obliga a trabajar para ellos. Esa que nos controla todos los días sin nosotros saberlo. Pero no puedo pararla. No soy tan especial. Sólo soy un anónimo. Y estoy solo (1x01).

Núñez Ladevéze (1985, p. 50) explica al reflexionar sobre 1984 de Orwell que se trata de "una distopía en el sentido etimológico y testimonial del término, en el sentido en que puede decirse que en su origen hubo una utopía, un lugar de ninguna parte que al encontrar su topos, su lugar terreno, se convierte en un mal lugar". Esto puede aplicarse a la sociedad actual en la que se inspira la narración de Mr. Robot. Desde la Antigüedad se creyó que la tecnología liberaría al hombre (mito de Prometeo). Sin embargo, en la sociedad globalizada de 2015 que de forma sinecdóquica se representa a través de las aventuras del grupo de jáquers neoyorquinos, la tecnología es la principal aliada del capitalismo salvaje y deshumanizado que encarna E Corp.

Por otro lado, la tecnología es también la principal aliada de Elliot, la que le ayudará a dar un golpe al sistema con el objetivo de que los ciudadanos puedan construir otro más justo, donde haya dignidad y libertad. Sin embargo, como se verá a medida que la serie avanza, esta utopía de Elliot se convierte nuevamente en una distopía.

\subsection{Elliot Alderson como héroe dúplice}

Durante las dos primeras temporadas de la serie se muestra a Elliot como un héroe movido por su afán de justicia social que le lleva a arriesgar su vida y a poner su sabiduría al servicio de la causa que lidera. El objetivo de la Revolución del 9 de Mayo es derrocar un sistema injusto, en el que una élite actúa de forma tiránica, al explotar, alienar y hacer infelices a una mayoría de ciudadanos.

Elliot quiere acabar con E Corp para vengar la muerte de su padre, víctima de un vertido tóxico de la empresa pero, sobre todo, como ya hemos indicado, para liberar a los ciudadanos de sus cadenas. Sin embargo, a medida que la trama se va complicando ya que los resultados de la revolución son opuestos a los que se preveían, veremos en él algunos comportamientos altivos, imprudentes y violentos. 
La dualidad es un componente fundamental de Elliot. Se refleja claramente en el trastorno de identidad disociativo que padece y se materializa en la lucha entre dos de sus personalidades: Mastermind y Mr. Robot. Aunque la mayoría de las veces adopta una conducta basada en la introversión, la duda y el apocamiento hay ocasiones en las que, como acabamos de indicar, lo dominan la arrogancia, la temeridad y la violencia.

La arrogancia y violencia se reflejan, sobre todo, en varios capítulos de la tercera temporada. Por ejemplo, cuando Mr. Robot se dirige a Krista, la psiquiatra de Elliot, como "sweetheart", "beautiful", "lady", "sexy" y "foxy".

Mr. Robot: Elliot nunca me dijo lo atractiva que eras. Para ser loquera eres bastante sexy (...) ¡Venga! ¿Nunca has pensado en liarte con uno de tus pacientes? (...) ¡Vaya! Guapa y lista (...) ¡Tú no entiendes una mierda! Sólo eres otra tía falsa que va de amiga" (3×02).

Mr. Robot: Me alegra volver a verte, guapa (...) ¡Mira a tu alrededor, guapa! (...) ¡Pon las noticias, guapa! (3x07).

Mr. Robot se comporta de nuevo de forma arrogante y violenta mientras apunta a Wellick con una pistola y lo golpea.

Mr. Robot: Nunca apeles a la bondad de un hombre. Puede que no tenga (...) No olvides de quién es el plan.

Tyrell Wellick: Antes creía que eras un dios. Te adoraba. Ahora veo lo imbécil que fui yo y lo inferior que eres tú. ¡Eres una puta cucaracha! Es la última vez que la cagas. Yo tomo el mando. Así que este ya no es tu plan, es el mío.

M.R: (lo golpea contra la pared). ¡Escúchame, sueco de mierda! Esta es mi revolución. Yo soy su creador, ¿entendido? Si estás aquí es porque yo te lo permito. Recuerda que podría haber apretado ese gatillo dos veces (3x04).

Con Krista se jacta de ser el creador de la Revolución del 9 de Mayo.

Krista: Así que eres un colaborador del 9 de mayo.

Mr. Robot: ¿Un colaborador? ; De eso nada! ¡Soy el creador! (...)

K: Para ser honesta contigo, Mr. Robot, parecen delirios de grandeza (...)

M.R.: ¿Wellick? No. Él trabajaba para mí. Pero ni tú ni el resto del mundo lo sabréis jamás porque seguiréis tragándoos encantados esas perlas de semen azucarado que os meten en la boca ( $3 \times 07)$.

Ya como Mastermind se enorgullece ante el White Army de ser el mejor en su campo. 
Mastermind: Mientras vosotros estabais de brazos cruzados, incumpliendo los plazos y sin hacer nada, yo diseñé un programa que resolvería todos vuestros problemas (...)

Ayudante de White Rose: Es solo un hacker. ¿Por qué cree que es mejor que todo un ejército de personas iguales que usted?

Mastermind: Porque lo soy. Hice algo en un día que vosotros no pudisteis hacer en meses (3x10).

Sin embargo, habrá momentos en los que Mastermind y Mr. Robot logran un equilibrio, es decir, los dos cooperan. Se aprecia en la cuarta temporada y al final del sexto episodio de la tercera temporada (3x06) cuando Mastermind le explica a Mr. Robot que Wellick y el Dark Army se la están jugando. Logran detener la explosión en el edificio de E Corp de Nueva York pero no saben que están estallando otros 71 edificios a lo largo de todo EEUU.

Hay un momento clave en la serie desde el punto de vista de la dualidad de Elliot en el terreno ético-moral. En el sexto capítulo de la cuarta temporada $(4 \times 06)$ utiliza a una persona como un medio para alcanzar su fin. Extorsionará a Olivia, una trabajadora del Banco Nacional de Chipre, entidad en la que el Dark Army y el Grupo Deus tienen todas sus cuentas. Le pide que llame a su jefe para que éste entre en el sistema del Banco y él pueda conocer así sus claves. Ella se niega y Mastermind la amenaza con que perderá la custodia de su hijo.

Elliot: ¿Qué pasará si no pasas el test de drogas?

Olivia: ¿Qué has dicho?

E: Conozco tu pelea por la custodia. Si sales positiva en Oxicodona...

O: ¿Qué demonios dices? Llevo ocho años limpia.

E: No es así. (Entonces, Olivia cae en la cuenta de que el café que Elliot le trajo contenía droga).

O: ¿Me drogaste?

E: Tenía que asegurarme de que me escucharías (...) Si no haces lo que digo, pierdes a tu hijo.

O: ¿Por qué haces esto?

E: Se me estaba acabando el tiempo. Era la forma más fácil de convencerte (4x06).

Ante la presión, Olivia se desmorona e intenta suicidarse. Mastermind insiste igualmente en que haga la llamada. 
Elliot: Pude parar el sangrado. Estarás bien. Lo siento.

Olivia: No te creo.

Elliot: (Elliot le entrega el teléfono móvil para que llame a su jefe). Borraré todas las huellas de tu participación y de la de tu jefe. Nada estará vinculado a ti.

Olivia: ¿Sabes? Puede que trabaje para monstruos, pero tú eres uno. Y eres de la peor clase porque ni siquiera lo sabes $(4 \times 06)$.

Previamente, Elliot dominado por Mastermind se había ganado la confianza de Olivia haciéndole creer que se encuentran por casualidad en un bar. Se acuesta con ella, escucha sus problemas y comparte los suyos propios.

\section{CONCLUSIONES}

Los dos textos presentan dos sistemas político-sociales en los que los ciudadanos están totalmente dominados. Aunque $V$ de Vendetta se enmarca en un totalitarismo similar al Nazismo y Mr. Robot en una sociedad como la actual, las tecnologías son la clave del control en ambos. Se emplean para difundir discursos que encierran una serie de ideas y valores sin los que el sistema sería imposible.

Como hemos expuesto, en las formas arquetípicas y en los mitos, el héroe aparece marcado por dualidades, simbolismos de confrontación y aspectos contradictorios. En su aspecto más profundo, el héroe, que representa la proyección de la identidad, está siempre marcado por su "sombra", por aspectos misteriosos, oscuros o incontrolados del yo. La evolución de la ciencia ficción y la distopía crítica, sin duda, está relacionada con la expresión de este héroe de naturaleza dual, pero hay que añadir elementos en dicha evolución que explican por qué una parte importante de los protagonistas y héroes de textos modernos y posmodernos tienen rasgos de ambivalencia moral, de contradicción lógica o se sitúan a caballo entre universos inconciliables desde otros puntos de vista.

En este sentido, en los dos los textos analizados, la ciencia ficción y la distopía crítica funcionan como un espejo social para una civilización que está incapacitada para pensar en un futuro utópico. De ahí que sus protagonistas sean héroes con una doble naturaleza moral o una ambigüedad en sus valores. Así, el capitalismo tardío aparece como una época en la que las contradicciones, frustraciones y decadencia civilizatoria se canalizan en formas de héroes ambivalentes, amorales o criminales en ocasiones.

Este aspecto conecta con la crítica social distópica y puede ser una forma de satisfacer o rentabilizar la frustración, rencor o impotencia de los públicos. V de Vendetta y Mr. Robot son ejemplos de distopías críticas que ofrecen una especie de venganza o compensación. Reflejan también la confusión en los valores en el capitalismo tardío. $\mathrm{V}$ y Elliot Alderson no son villanos o malvados. Su conducta y su aventura resaltan una carrera vital difícil, en el límite de la normalidad y la moralidad. 
Ejemplifican la transición hacia un género de ciencia ficción en el que cada vez abundan más los héroes de naturaleza sombría, anómala o anormal que son la proyección de la identidad humana en el ecosistema actual caracterizado por la pérdida de valor de los grandes relatos del pasado.

Queda por discutir si estos rasgos son realmente nuevos o se trata de una simple modulación de las formas eternas del arquetipo del héroe dual, trasplantadas a una era particularmente oscura, que pasará finalmente.

\section{REFERENCIAS}

Aladro, E. (2013). Sobre el concepto de proyección en el mundo comunicativo. Revista Historia y Comunicación Social, 18, 317-329.

Aladro, E., Jivkova, D. y Bailey, O. (2018). Artivismo: un nuevo lenguaje educativo para la acción social. Comunicar, 57, (XXVI), 9-18. https://doi.org/10.3916/C57$\underline{2018-01}$

Bauman, Z. (2001). La posmodernidad y sus descontentos. Madrid: Akal.

Baudrillard, J. (2007). La sociedad de consumo. Sus mitos, sus estructuras. Madrid: Siglo XXI.

Bowcott, O. (2015). Thatcher tried to block 'bad taste' public health warnings about Aids. The Guardian, 30-12-2015. https://www.theguardian.com/politics/2015/dec/30/thatcher-tried-to-blockbad-taste-public-health-warnings-about-aids

Campbell, J. (1959). El héroe de las mil caras. México: FCE.

Campbell, J. (2016). El poder del mito. Madrid: Capitán Swing.

Eliade (1999). Imágenes y símbolos. Madrid: Taurus.

Eliade (2005). La isla de Eutanasius. Madrid: Trotta.

Fernández Pichel, S. N. (2013). “Amado monstruo. Lo heroico y lo monstruoso en Walter White", en Cobo, S. y Hernández, V. (coord.) Breaking Bad. 530 gramos (de papel) para serieadictos no rehabilitados. Madrid: Errata Naturae, 105-122.

Fitting, Peter (2010). Utopia, dystopia and science fiction. En Claeys, G. (ed.) The Cambridge Companion to Utopian Literature. Cambridge: Cambridge University Press, 135- 153.

Gimbutas, Marija (2014). Dioses y diosas de la vieja Europa. Madrid: Trotta.

Gimbutas, Marija (2019). El lenguaje de la diosa. Barcelona: Atalanta. 
Hermida, C. (20000). Crisis y restructuración del capitalismo: 1973-2000. Historia y Comunicación Social, 5, 255-270.

Hernández Santaolalla, Víctor y Hermida, Alberto (2016). Más allá de la distopía tecnológica: videovigilancia y activismo en Black Mirror y Mr. Robot. Index Comunicación, 6(2), 53-65.

Eliade, Mircea (1999). Imágenes y símbolos. Madrid: Taurus.

Eliade, Mircea (2005). La isla de Eutanasius. Madrid: Trotta.

Fitting, P. (2010). Utopia, dystopia and science fiction. En Claeys, G. (Ed.) The Cambridge Companion to Utopian Literature, Cambridge: Cambridge University Press, 135- 153.

Gimbutas, M. (2014). Dioses y diosas de la vieja Europa. Madrid: Trotta.

Gimbutas, M. (2019). El lenguaje de la diosa. Barcelona: Atalanta.

Hernández-Santaolalla, V. y Hermida, A. (2016) Más allá de la distopía tecnológica: videovigilancia y activismo en Black Mirror y Mr. Robot. Index. comunicación, 6(2), 53-65.

Jameson, F. (1991). El posmodernismo como lógica cultural del capitalismo tardío. Buenos Aires: Imago Mundi.

Jung, C. (2002). Mysterium Coniunctionis. Madrid: Trotta.

Jung, C. (2008). La vida simbólica. Madrid: Trotta.

Jung, C. (2011). Aión. Contribuciones a los simbolismos del sí mismo. Madrid: Trotta.

Hermida, C. (2000). Crisis y restructuración del capitalismo: 1973-2000. Historia y Comunicación Social, 5, 255-270.

López Keller, Estrella (1991). Distopía: otro final de la utopía. REIS (Revista Española de Investigaciones Sociológicas), 55, 7-23.

Lyotard, J. F. (1992). ¿Qué es lo posmoderno? Zona Erógena, 12, 1-10.

Moore, A. y Lloyd, David (2015). V de Vendetta. ECC Ediciones: Barcelona.

Morin, E. (2001). El cine o el hombre imaginario. Barcelona: Paidós.

Miller, T. \& McHoul, A. (1998). Popular Culture and Everyday Life. Londres: Sage.

Moylan, T. (2018). Scraps Of The Untainted Sky: Science Fiction, Utopia, Dystopia. Nueva York: Routledge. 
Novell Monroy, N. (2008). Literatura y cine de ciencia ficción. Perspectivas teóricas. Barcelona: Universidad Autónoma de Barcelona.

Núñez Ladevéze, L. (1985). De la utopía clásica a la distopía actual. Revista de Estudios Políticos, $\mathrm{n}^{\mathrm{O}} 44,47-80$.

Picart, C. J. (2003). Remaking the Frankenstein Myth on Film. Between Laughter and Horror. State University of New York Press: Nueva York.

Richards, Ch. (2011). Entrevista a Alan Moore. Disponible en: https://siguealconejoblanco.es/comics/comic-americano/entrevista-a-alanmoore/

Thomas, P.A. (1993). The nuclear family, ideology and AIDS in the Thatcher years. Feminist Legal Studies, 1, 23-44. https://doi.org/10.1007/BF01191523

CONTRIBUCIONES DE AUTORES Y FINANCIACIÓN: Contribuciones de las autoras: Conceptualización, Requeijo Rey, Paula, Aladro Vico, Eva; metodología, Requeijo Rey, Paula, Aladro Vico, Eva; software, no procede; validación, Requeijo Rey, Paula, Aladro Vico, Eva; análisis formal, Requeijo Rey, Paula, Aladro Vico, Eva; redacción -preparación del borrador original-, Requeijo Rey, Paula, Aladro Vico, Eva; redacción-revisión y edición, Requeijo Rey, Paula, Aladro Vico, Eva; supervisión Aladro Vico, Eva; administración de proyectos, Aladro Vico, Eva. Las autoras han leído y aceptado la versión publicada del manuscrito.

Conflicto de intereses: las autoras declaran que esta investigación no supone ningún conflicto de intereses.

\section{AUTORAS}

\section{Paula Requeijo Rey:}

Profesora Ayudante Doctora en la Facultad de Ciencias de la Información de la Universidad Complutense de Madrid. Premio a la Excelencia Docente UCM durante el trienio 2018- 2021. Acreditada como Profesora Contratada Doctora por la Aneca. Secretaria de la revista Cuadernos de Información y Comunicación y miembro del instituto de Investigaciones Feministas. Investigadora visitante en la Universidad de California (EEUU) y en la Universidad Nacional Autónoma de México (UNAM). Grupo de investigación consolidado Estructuras Comunicativas e Interacciones en los distintos niveles de la Comunicación Interpersonal de la Universidad Complutense. Ha participado en más de una docena de proyectos de investigación incluyendo tres europeos y varios I+D. 50 trabajos publicados, indexados en primeras posiciones y editoriales. Escritora de dos libros de poesía.

Orcid ID: https:/ / orcid.org/0000-0003-2801-9996

Google Scholar: $\underline{\text { https://scholar.google.es/citations?user=hZh-1MQAAAAJ\&hl=es }}$

Academia.edu: https://ucm.academia.edu/PaulaRequeijo

Researchgate: https://www.researchgate.net/profile/Paula-Requeijo 


\section{Eva Aladro Vico:}

Profesora Titular de la Facultad de Ciencias de la Información de la Universidad Complutense de Madrid. Acreditada a Catedrática de Universidad en 2020. Directora de la revista Cuadernos de Información y Comunicación y del Grupo Consolidado de Investigación Estructuras Comunicativas e Interacciones entre los distintos niveles de la Comunicación (940820) de la UCM. Premio a la Excelencia Docente del curso 20152016 y Premio Docentia trienio 2017-2020. Sus publicaciones constituyen 160 textos con decenas de artículos científicos en las revistas de impacto internacionales y en nuestro país y una cincuentena de capítulos de libro y monografías completas en editoriales de la cabecera internacional en su sector. Entre sus libros: Teoría de la Información y la Comunicación Efectiva, La Información Determinante o Las Diez Leyes de la Teoría de la Información. Profesora Invitada en las Universidades de Frankfurt (Alemania), Melbourne (Australia), Tesalónica (Grecia), Atenas (Grecia), Creta (Grecia), Cagliari (Italia) y Monterrey (México). Portavoz de la Plataforma de Ayuda al Teatro Albéniz, de la Plataforma para la Reestructuración en la Universidad Complutense de Madrid, así como escritora de un blog y de seis libros de poesía.

Orcid ID: https:/ / orcid.org/0000-0003-1986-8312

Google Scholar:

https://scholar.google.com/citations?user=MdVEEs4AAAAJ\&hl=en

Academia.edu: https://ucm.academia.edu/EvaVico

Researchgate: https://www.researchgate.net/profile/Aladro-Eva 